\title{
Chinese Students Negotiating L2 English Writing Identity: Navigating Introductory Composition at a U.S. University
}

\author{
Jennifer Lund
}

\begin{abstract}
This small scale ethnographic study explores the L2 English academic writing identity negotiation of three Chinese students within the context of an introductory composition course at a U.S. Midwestern university focused on the needs of international students. Through individual interviews and classroom observations, it was investigated whether participants' previous language learning experiences and current language ideologies play a significant role in their attitudes towards acquiring L2 academic literacy skills in English. Another point of interest was how these students shape their 'imagined communities' in respect to second language writing and whether they experience any kind of 'inferiority of identity'. Results concluded that students were implicitly and explicitly aware of English as a dominant discourse and were able to describe specific stylistic differences between Chinese and English argumentative writing that seemed to have some effect on their conscious development of thought patterns in organizing writing assignments in a given socio---cultural setting. Further notice of how L2 students accommodate or resist English academic writing conventions and how they may self---marginalize their own L1 merits greater attention.
\end{abstract}

Keywords: multilingual writers; first-year undergraduates; identity investment; imagined communities

\section{Introduction}

In the past decade or so there has been an influx of Chinese undergraduate international students in U.S. universities. According to the most recent 2013-2014 Open Doors Report from the Institute for International Education, there were 274,439 Chinese students (comprising 31 percent of total international students in the U.S.) studying in U.S. colleges and universities, which makes China the leading country of origin in front of India, South Korea and Saudi Arabia. As noted in Chowdhury and Phan (2014), reasons for this phenomenon may include educational factors such as crowding at top universities in China and pressures in achieving high scores on the College Entrance Exam (Gao Kao exam). The authors also cited high rates of youth unemployment in China as another factor along with the possibility of increasing the student's marketability by studying abroad. Studying abroad can be 
seen as a way to increase chances of getting employment back in China upon graduating from a well-regarded U.S. university.

As an instructor at a research university where the international Chinese student population is steadily increasing in line with current trends amongst major research universities across the U.S., my first-year undergraduate composition course titled "Reading, Writing, and Inquiry" designed for English L2 writing students is comprised of mostly Chinese students. Furthermore, this course, which involves mastering fundamental skills in English academic reading and writing, serves as a gatekeeper for full admittance to programs in the School of Business, which are generally highly-regarded by Chinese international students pursuing undergraduate degrees abroad. Students who succeed with a B or better in this course qualify for admittance to the Business School provided that they also do just as well in their other courses. Therefore, the introductory composition course has a powerful connection to gaining what Bourdieu (1991) would term linguistic capital associated with the dominant discourse of English in academic circles in the most economically developed countries around the world. In the current study, I am primarily interested in how international Chinese students negotiate forming their identity as L2 writers of academic English under the circumstances highlighted above. This involves determining what kinds of investment they have in joining imagined communities that they may believe will bring them economic, academic, and social success both in their study abroad environment of the U.S. and back in their homeland of China. In addition, there has been little speculation as to how the dominant language ideology of English in Western universities may be affecting students' overall language identity. It can be questioned whether these students will be made to feel perpetually inferior as "others" in an English dominant society where a knowledge of English has become ever more prominent in these students' ideal image of success.

\section{Literature Review}

The concept of identity can be approached from several angles, but this literature review will focus on how it may be constructed by L2 language learners in a higher education setting. To begin, Norton (1997) provided a coherent link between multilingual learners' identity and the concept of symbolic power (Bourdieu, 1991). Norton (1997) explained that attaching a value to a certain kind of speech (or writing) results in unequal power structures between dominant and less dominant discourses. She defined identity as "how people understand their relationship to the world, how that relationship is constructed across space and time, and how people understand their possibilities for the future" (p. 410). For example, investment as intertwined with learners' self-image in gaining competence in the target language of English has to be considered through the lens of "multiple desires" that shape each individual's social identity (p. 411). Norton and Toohey (2011, p. 411) also maintained that learners can be very flexible in changing their identity options to move closer to the inner circle of participation in communities of practice regarding the target language of English. By making an effort to participate more fully in the community of practice of native speakers of English, they were given legitimacy to 
gain symbolic capital in the form of social and linguistic capital.

Chiang and Schmida (1999) took things one step further and considered how linguistic identity affects Asian American students studying in the College Writing Program at UC Berkeley. The authors focused on, among other things, the "impact of the disharmony among language use, language identity, and language ownership on their development as English language users" (p. 91). By using a constant comparative method, the researchers created their own "tentative" theories and then accepted or rejected them based on the collected data, which took the form of an open-ended survey, interview questions, and student writing portfolios. Through these methods, they found evidence of conflict between linguistic identity and linguistic ability in writing practices. Several themes emerged such as bilingual identity versus bilingual literacy and native versus nonnative identity issues. For example, one student commented:

How can I give myself an American identity if I cannot even feel connected to the American language myself? By saying connected, I mean the feeling of owning the language and, therefore having full authority over it. It does not matter how frequently I use English, somehow I can never feel that I own it (p.89).

This quote challenges seemingly black and white concepts of native versus nonnative and what bilingual actually means. It is another example of how the borderlines between languages in multilingual writers are blurred both culturally and linguistically.

Furthermore, L2 writers are constantly adjusting their social and linguistic identities due to their investment in what Norton (2001) termed 'imagined communities', which could be defined as groups of people that an individual connects with through the imagination in an intangible way. How L2 writers position themselves in such imagined communities gains in importance when considering an individual's investment in developing and negotiating a writing identity in a given language. Canagarajah (2004) investigated how L2 writers strategize writing voice to conceptualize their identity in academic discourse by using Atkinson's (1999) instrument of rhetorical analysis to analyze the following: patterns of avoidance in integrating self-identity with the dominant discourse, transposition of self-identity with the dominant discourse, accommodation to consciously adopt dominant discourse, and conscious opposition to the dominant discourse. He concluded that voice is indeed negotiable when in the context of identity construction and dominant discourses should be analyzed critically.

To complicate the issue further, it can be understood that L2 writing identity must be viewed in a unique way that is different from a monolingual perspective. Liu and Tannacito (2013) explored how the dominant discourse of academic English may or may not influence Taiwanese second language learners in a U.S. university Intensive English Program to reconstruct their identities. The authors looked at racial and language ideology influences such as language privilege and White Prestige Ideology. They also considered how various forms of social and linguistic capital may affect students' motivations to invest in the imagined community of the American university. Results of this qualitative study indicated that L2 writers of 
English do indeed express elements of resistance to the dominant discourse of standard written English, but that this also depended on their level of investment.

\section{Background on the Chinese Educational System}

Kipnis (2011) provided an in-depth look at educational desire within a Chinese primary and secondary educational context and gives a vivid portrayal of how culture can manifest itself within the classroom. He discussed the importance placed on handwriting Chinese calligraphy and characters as a way of showing the "quality" of the student. In this text, education for quality refers to the development of one's character through creativity classes at the primary school level and an attempt to promote more critical thinking skills in reading and writing classes. The author mentioned how the implementation of the one-child policy in 1981 has many parents anxious for their "son to become a dragon" and "their daughter a phoenix", a popular saying meaning they want them to be as powerful as imperial royalty. Interestingly, the text goes on to explain that this desire for greatness seems to be manifested as possible through educational glorification. It stated that 100 percent of parents surveyed in both rural and urban and rich and poor areas of China agree that higher education is the most important thing for their children, regardless of whether it will get them a job. Kipnis (2011) also emphasized the role of the teacher as model and the importance of speaking and writing Standard Mandarin as part of a nationalistic and Pro-Party curriculum. He also mentioned the absence of a school counterculture. While he does acknowledge an anti-rural prejudice, there is an absence of working class anti-school culture. Whether such cultural constructions in the Chinese educational system filter down into the mindsets of Chinese international students studying in the U.S. remains to be investigated in the following analysis.

\section{Theoretical Framework}

Studying identity construction in L2 English writing is important because it has sociopolitical undertones and ideological implications in how authorial voice is regarded as acceptable or non-acceptable in the dominant discourse. Bourdieu's (1991) theories regarding various kinds of capital (social, cultural, and linguistic) and habitus are useful in taking a critical approach to writing instruction. One way of approaching this is to consider how the legitimacy of language use may be connected to "self-marginalization". Kumaravadivelu (2006) described this as legitimating the hegemony of the dominant discourse and a "superiority of Western methods over local practices" (p. 219). In this way, the habitus of English academic writing practices in the western university positions the English L2 student as an 'Other' or outsider. This is helpful when considering how L2 writers may think of themselves in the context of a U.S. university introductory composition course.

In order to explore this further, the current study will consider the following research questions:

1. Do Chinese students' language learning backgrounds play a role in their attitude towards acquiring L2 English literacy skills? 
2. How do Chinese undergraduate L2 writers at a Midwestern U.S. university negotiate their academic writing identity in the context of an introductory composition course designed for international students? Is there any evidence of resistance by Chinese international students to academic writing conventions within an introductory composition classroom?

3. Is there any indication of an "inferiority of identity" amongst Chinese international students in an English dominant university setting?

\section{Method Setting}

The site for this study is a public research university located in the Midwestern United States. The university has a high enrollment of undergraduate international students with the most significant number coming from China. The classroom setting within this university was an English Department introductory composition course termed as designated for 'multilingual' students and typically populated by freshman and sophomore students. In this case, the term 'multilingual' refers to students whose first language is not English. The course is meant to provide rigorous training in college-level writing and research with an emphasis on critical thinking, analytical writing, and synthesis of ideas from secondary sources. While it is designed to model a similar course for undergraduate native speakers of English with similar course assignments and workload, the multilingual version provides more support in understanding conventions of western academic writing style and a greater focus on specific lexical and linguistic concerns. Students take part in a sequenced writing project that culminates the course where they choose and introduce a debatable issue, conduct research on it, and then write a persuasive argument using secondary sources as evidence (see Appendix A). The course is required for all incoming freshman and serves as a gateway to the Business School which requires a grade of B or better on all courses in the first year of studies for full admission to their programs of study. Unsurprisingly, business is the most popular choice of major with international Chinese students.

\section{Participants}

The three focal participants were recruited from the above mentioned introductory composition course that consisted of 14 students total (12 Chinese, 2 Koreans). As noted in the table below, all three participants were freshmen undergraduate Chinese students. Students had a choice between selecting pseudonyms in Chinese or English. Interestingly, all three students self- selected fairly uncommon English pseudonyms: Fiona, Kelvin, and Levitt. (See Table 1 below). 
Table 1

\begin{tabular}{|c|c|c|c|}
\hline & Fiona & Kelvin & Levitt \\
\hline Age & 19 & 19 & 19 \\
\hline Gender & Female & Male & Male \\
\hline $\begin{array}{l}\text { City/Country of } \\
\text { Origin }\end{array}$ & Shenzhen, China & $\begin{array}{l}\text { Anhui, China (birthplace) Ningxia } \\
\text { Autonomous Region, China } \\
\text { (currently) }\end{array}$ & Beijing, China \\
\hline Native Language & Cantonese & Mandarin & Mandarin \\
\hline $\begin{array}{l}\text { Year at } \\
\text { university }\end{array}$ & Freshman & Freshman & Freshman \\
\hline $\begin{array}{l}\text { Major at } \\
\text { university }\end{array}$ & Art Management & Business & Business \\
\hline $\begin{array}{l}\text { Spring } 2014 \\
\text { university } \\
\text { coursework }\end{array}$ & $\begin{array}{l}\text { Museum Management, Art } \\
\text { History, Economics, } \\
\text { French, English } \\
\text { composition }\end{array}$ & $\begin{array}{lr}\text { Microeconomics, } & \text { other } \\
\text { undetermined, } & \text { English } \\
\text { composition } & \end{array}$ & $\begin{array}{l}\text { Accounting, } \\
\text { Computer } \\
\text { Science, } \\
\text { Astronomy, Art } \\
\text { History, English } \\
\text { composition }\end{array}$ \\
\hline $\begin{array}{l}\text { Primary/Middle } \\
\text { School } \\
\text { Educational } \\
\text { Setting }\end{array}$ & $\begin{array}{l}\text { British International Middle } \\
\text { School in Beijing-1 year } \\
\text { (instruction in English), } \\
\text { Chinese public middle } \\
\text { school in Shenzhen-2 years } \\
\text { (instruction in Mandarin) }\end{array}$ & $\begin{array}{l}\text { Chinese public middle school-3 } \\
\text { years (instruction in Mandarin) }\end{array}$ & $\begin{array}{l}5^{\text {th }} \text { grade of } \\
\text { primary } \\
\text { school - } 4 \text { native } \\
\text { English speakers } \\
\text { taught courses in } \\
\text { English at his } \\
\text { school }\end{array}$ \\
\hline $\begin{array}{l}\text { High School } \\
\text { Educational } \\
\text { Setting }\end{array}$ & $\begin{array}{l}\text { British International High } \\
\text { School in Shenzhen-3 years } \\
\text { (instruction in English) }\end{array}$ & $\begin{array}{l}\text { Chinese public school-1 year } \\
\text { American public school in San } \\
\text { Jose, CA-1 year } \\
\text { American private Catholic school } \\
\text { in Fresno, CA-2 years }\end{array}$ & $\begin{array}{l}\text { Private High } \\
\text { School in Beijing } \\
\text { (instruction in } \\
\text { Mandarin) - } 3 \\
\text { years }\end{array}$ \\
\hline
\end{tabular}

\section{Data Collection}

Data were collected using ethnographic methods including classroom observation, field notes, and one-on-one interviews. The observations were conducted during nine regular class sessions after gaining permission from the instructor whose native country of origin was Singapore. During the initial first few observations, the main objective was to take detailed notes and gather a rich description regarding 
teacher-led and student-led classroom activities such as students' interactions within groups, languages used, student interactions with the teacher, body language, and apparent engagement or disengagement with the task at hand.

Subsequent observations focused on the three focal students (see Table 1) who agreed to take part in the study and included the same objectives as mentioned above. Before collecting observation or interview data, the three participants were invited to sign a consent form allowing me to observe them during 2-3 class sessions and asking them to participate in three 30-40 minute individual interviews (two longer interviews in Fiona's case) at a time of their choosing.

The semi-structured interviews were held in a small room near the classroom site that afforded privacy and confidentiality to the participants. They were conducted in English, the common language of the researcher and participants, and digitally recorded using a voice recorder on an iPhone. Handwritten notes were also taken as a backup to the recording. The focus of the first interview centered on extracting biographical information regarding educational background and language learning experiences prior to attending university. Then the focus turned to their current goals of learning English and questions related to English academic writing and personal writing identity. The second interview focused more on similarities and differences between English and Mandarin academic writing. Finally, the third interview inquired about the curriculum and assignments in their composition course. Guided by the three groups of questions, students were encouraged to elaborate on certain questions more than others and as time went on, certain questions were found to be redundant and were dropped. (See Appendix B for a list of interview questions).

\section{Data Analysis}

Descriptive coding (Saldaña, 2009) was used throughout the analysis of interview transcriptions to look for themes that appeared to be central to the focus of the research questions. An analysis of emerging themes from the descriptive coding of interview transcriptions will allow for discussion of the interview data. Triangulation was achieved primarily by using this method with field notes, interviews with participants, an interview with the instructor, and member checking of interview data during the course of the interview by asking the same question in different ways to be sure answers remained consistent.

\section{Findings}

\section{Recognition of English as a Dominant Discourse}

In analyzing the interview transcripts of the three participants, the importance of learning English because of its global role as a dominant discourse in education and business was one of the first major themes to emerge. This became evident in the first interview when each student's language learning backgrounds were explored. The following will provide a brief summary of each participant's language learning background and ways in which the dominance of English was acknowledged during these conversations and intertwined with each individual's language ideology. 


\section{Fiona}

As each of the three participants was asked to elaborate on their experiences learning native and additional languages both inside and outside the classroom, Fiona's case was particularly interesting because of both parental influences and the variety of language learning settings she experienced in middle and high school. Her Cantonese mother born in Hong Kong used to live and work in Switzerland where she spoke French and her mainland Chinese-born father studied abroad in Canada and spent time working in Singapore. In addition to her parents' international experiences, Fiona grew up observing her father who made part of his living as an antique dealer in Beijing and often made business transactions in English. As a result of her father's hobby collecting antiques in Beijing, Fiona was given the chance to study at an international English-medium middle school in Beijing for one year before returning to a Mandarin-medium middle school in Shenzhen for another year. During her high school years she transferred again to a British Englishmedium international school where she recalled several negative interactions with one of her English teachers who she described as being strict for enforcing an English-only rule in the classroom with severe repercussions for speaking Chinese. However, she acknowledged the importance of using English in an Englishdominant environment with the example of a friend who had gone to study in the U.K. and returned to China with little improvement in his English speaking skills. She saw mixed L1 classes as being more beneficial to encourage more English use in the classroom and seemed disappointed that her U.S. university composition course was composed primarily of Chinese L1 students, forcing her to sometimes interact in Chinese during the class when prompted by her peers. In addition, she saw her education in a U.S. university as an "investment" because of the "high quality of education", making her feel it even more necessary to be proficient in the dominant language. Therefore, she explained further that her English writing ability takes dominance over her Chinese writing ability in an American context.

\section{Kelvin}

Kelvin's language learning background was also spent largely in an English dominant environment because he attended three years of high school in the U.S. by what he says was his own choice. After one year in a public high school in China, his first year in the U.S. was spent at a public high school in San Jose, California with a transfer to a private Catholic school in Fresno, California for his final two years. Similar to Fiona, he enjoyed being in an English dominant environment because of greater opportunities to improve his speaking skills. He also acknowledged that "you learn more cogent things for high school", which could be interpreted as meaning that his high school education in the U.S. was deemed to be more useful to him. This could stem from Kelvin's remembrance of his father's description of the U.S. as "the head of our country like 20 years or 10 years". He goes on to say that "if you learn...take the education there (U.S.) you would...might have more future vision than other Chinese people". This statement seems to indicate a powerful parental influence in shaping his beliefs about the value of a U.S. education and the necessity of immersion in an English dominant environment to provide perceived 
benefits in gaining a more forward thinking ideology. It's not clear, however, what exactly he meant by "future vision".

\section{Levitt}

With his primary and secondary education in Beijing, Levitt spent all three years of high school at a private school in Beijing with Mandarin as the language of instruction. While he benefited from native English speaking teachers for his English courses in primary school, he had a strong grounding in Chinese argumentative writing in high school to a much greater extent than Fiona and Kelvin. In addition, he spent his high school years preparing to take the TOEFL and SAT in order to gain admittance to an American university. Perhaps because he grew up learning English in an EFL context, he mentioned the importance of understanding English culture in addition to improving speaking and writing skills. While what he means by "English culture" would need to be defined further, it is interesting that he recognized language learning as being attached to culture in an environment where a focus on grammar and rote learning is prevalent (Kipnis, 2011). In addition, this is surprising considering his understanding that correct grammar is weighted more heavily on the English exam (not clear if he meant the Gao Kao or the TOEFL). One interpretation of this could point to his understanding of the dominance of English on a global scale and his individual need to understand it on a level outside of standardized exams. Further evidence of this belief can be found in his statement that "more people can read English than Chinese in different countries around the world". He also recognized that academic English is "standardized and a formal and official way of writing".

Furthermore, he talks of using writing as a tool and explains that because he is studying in the U.S., English writing is used more frequently than Chinese and, as a result, has become more important to him. He has noticed that his Chinese writing has deteriorated because he hasn't practiced it in over a year. This seems to be in line with both Fiona and Kelvin's statements that English speaking and writing must take precedence over Mandarin because of their need to succeed in a U.S. university context.

\section{Awareness of Style Differences between Chinese and English Argumentative Writing}

In the second interview (first interview for Fiona), all three participants seemed to have a keen awareness of style differences between Chinese and English argumentative writing, which is a genre closely associated with academic writing and one that requires mastery for standardized exams such as the TOEFL, the Chinese University Entrance Exam (Gao Kao), and U.S. university introductory composition courses. Style can be associated with such factors as coherence and cohesion, citation formats, sentence structure, syntax, word choice, grammar, punctuation, and level of formality (Farris, 2014). Additionally, only Kelvin had formally practiced citing sources before taking introductory composition at the university level because his U.S. high school teacher insisted on giving students exposure before college. 
The importance of "grammar" in English academic writing was a topic mentioned by more than one person. I put the word "grammar" in parentheses because upon further questioning I came to realize that what the students were calling "grammar" actually meant organizational factors related to coherence and cohesion, such as use of transition words, rather than syntactical constructions. Kelvin explained that Chinese writing is more "freestyle" at the high school level to prepare students to take the Chinese writing portion of the university entrance exam. When pressed what "freestyle" means, he said that it related to the logic or organization of the writing.

One of the most interesting findings in this category, however, had to do with each participant's overall agreement that Chinese argumentative writing is not only "freestyle", but also what Levitt termed as "ambiguous". While Levitt defended this "weakness" (his words) of Chinese argumentative writing as dependent on cultural context, he also said that English is a "faster way to communicate" and not as "indirect" as Chinese. Fiona backed this up by noticing that U.S. students in her mainstream university courses have "really clear organization", which could be interpreted to mean that they get their points across concisely and in a logical manner that is easily understood. Levitt shed more light on this by saying that Chinese argumentative writing is more tolerant of a narrative style and legitimate evidence could include the insertion of the writer's own experiences as opposed to what he terms the formulaic writing style of English argumentative writing that is based on scientific logic with less "esoteric" word choices, which he judged to be easier for readers to understand and follow. While he seemed to recognize certain benefits of writing in an English argumentative style, an internal conflict of style choice between Chinese and English argumentative writing often made him feel "restricted" (my words) when writing in English as illustrated in the following quote:

...it's hard for me to choose between the formula I always follow (formulas he learned from his high school English teacher to prepare for the TOEFL exam) as opposed to the exposure of my own experience. (Levitt, Interview 2)

Fiona also seemed to make a similar realization by noting how style affects the audience's reception of the writer's ideas and how what she termed as the "U.S. professional structure" makes it easier to understand "lots of information". Kelvin put it the most bluntly in saying that "the logic between Chinese people and Western people is different". The fact that he chose to polarize writing into what he called "Chinese" and "Western" shows that he does seem to distinguish some kind of style distinction between his L1 and L2 and this could be key in how he chooses to negotiate his writer identity. In the meantime, it can be ascertained that all three participants could identify key style differences between Chinese and English argumentative writings and were trying their best to find a way to cope in the sociocultural environment of a U.S. university setting as L2 writers. Some examples of coping skills mentioned in the interviews included getting help from the instructor, comparing their papers with those of native English speakers, and reading what Kelvin dubbed "outstanding writings" to notice style differences. Interestingly, 
Fiona who is studying French in a U.S. university context mentions the role of the Alliance Française in France to enforce standardization of French formal written discourse. In agreement with the premise behind this French institution to regulate French written discourse to uphold a certain level of formality, she believes that there should be some kind of standard to uphold for every language because it helps others learning the language. This reasoning seems to be in direct opposition to what Canagarajah (2013) would define as a more translingual practice where acceptance of different writing styles is accepted and encouraged even in formal discourse.

\section{Negotiation of L2 English Writer Identity}

Throughout all three interviews (two longer interviews in Fiona's case), there were many references made to negotiation of writer identity. While some of the above discussion on Mandarin and English argumentative writing styles could also pertain to identity construction, this category on negotiation of L2 English writer identity will focus more on specific references to writing identity and its development in the context of a university-level introductory composition classroom.

To illustrate one overlap with the previous category on writing style, Levitt's agreement with me that he felt "restricted" (my words) shows his possible aversion to what he perceived to be the formulaic style of English academic writing versus what he termed as the more narrative style used on the Chinese writing portion of the Chinese university entrance exam. The following

quote provides further evidence of this:

If we just randomly write in our own way, it probably will be better for us to express our ideas or our experience. It provides us with more space for imagination and to reveal what we really thought about the topic. (Levitt, Interview 2)

However, his concession, which was similar to Fiona's regarding the Alliance Française, that a "specific like structure" is better for readers of different backgrounds trying to understand his thoughts points towards a writing identity that is in a process of transition and negotiation.

Beyond noticing certain benefits of one writing style or another, Levitt also mentioned the idea of adjusting actual thought patterns for organizing argumentative writing in explaining how it is useful to read works by native English speakers in order to "adjust logics". This idea surfaced even more in Kelvin's reflection on the process of writing a critical argument paper for his introductory composition course at a U.S. university:

...learn writing in English make me change my thoughts sometimes. Like when you write, you don't think Chinese way. You think Western way like how Western people may see these questions...you just write down...you don't have Chinese in your thoughts and then translate to English. You don't do that. You will look at the problem in an American way. (Kelvin, Interview 1)

It can be taken for granted that this ability to think in a "Western way" likely has something to do with the language learner's level of English proficiency. Fiona, who acknowledged that she never spent much time writing in Chinese due to her years 
spent in international schools, noticed that she had difficulty understanding her Chinese roommate's paper. Her roommate told her that she thinks in Chinese first and then translates into English when writing. Fiona discovered that when she thought of it in a Chinese way, she could make more sense of it. Therefore, this seems to point towards not only L1 interference from a syntactical standpoint, but also a socio-cultural influence in how international students might approach L2 writing within a given context.

Fiona's superior exposure to the L2 environment previously in China may have made her doubly sensitive to a given socio-cultural context when writing and allowed her more chance to develop a stronger L2 writing identity. She also recognized that her critical writing skills in English helped her critical thinking skills, which she claimed were a result of developing her English academic writing skills in high school. The following is an anecdote regarding her shift in viewpoint towards China's one-child policy:

When I came to American, there is lots of people ask me ... 'do you have a sister or brother?' I always say, 'no, I'm the only child in my family.' I feel really weird because they all have sister or brother here.

Before I learned critical writing in my high school, one-child policy is not a good thing. It's unfair for most of people in China because they not let the...because lots of children in China will become very selfish because they are only one child. And after I write critical thinkings, I talk about some good things of this policy and some bad things. It's more influence the way I'm thinking. When I met some problems, I won't say only from one aspects of the issue. I probably will stem out of the issue and more aspects of the things. (Fiona, Interview 1)

One caveat here is the fact that regardless of whether her critical writing skills play a role in the development of her critical thinking skills, this in no way assumes that writing in English is a key factor. It is possible that her critical writing skills would have become just as developed in Chinese had she had more exposure. What is evident here is that her thought processes expanded, or "stemmed out" as she said, as a result of developing her writing skills in the genre of the argument paper. Further research would be needed to determine if this development of critical writing skills could take on a different form in an L1 such as Chinese versus an L2 such as English.

\section{Discussion}

In light of the evidence presented above, it seems that all three participants drew on various socio-cultural influences in their family and previous language learning environments to have both positive and negative effects on their attitudes towards developing their L2 English literacy skills. To highlight one example, Fiona's learning experiences in English-only classroom settings seemed to have a positive effect in that they helped her gain confidence in her oral and written language skills and instilled an importance of allowing opportunities to practice English. This was also evident during classroom observations of her U.S. university introductory composition course where she was frequently observed asking and answering questions voluntarily during full class feedback sessions and made an effort to speak English during class sessions. She was, however, sometimes noted to be speaking Chinese with other group members, but this could also be because her instructor, a 
Singapore-born English speaker who I also interviewed, stated that she did not discourage students from speaking Chinese during class sessions. On the other hand, the strict English-only atmosphere at her British-medium high school seemed to affect her negatively and ultimately discouraged her from studying in the U.K.

In looking at negotiation of identity and investment in L2 English academic writing, Bourdieu's (1991) notion of linguistic capital appears in the foreground in numerous references by each of the three participants regarding the dominance of English on a global scale. From Fiona's experience with an EFL teacher in China enforcing an English-only classroom to Levitt's desire to understand more about English culture to gain entrance to an imagined community, there seems to be a conscious recognition that English is a form of linguistic capital to be gained. The interview with the students' university composition instructor also revealed that students were generally compliant by unquestionably following writing assignment descriptions, structuring logical arguments, and conforming to APA or MLA citation formats.

Classroom observations also revealed that the focal students in this study appeared invested in learning the material presented and remained on task and focused for the most part. Likely because of their high levels of investment in learning standard academic English (Norton, 1997; Norton \& Toohey, 2011; Liu \& Tannacito, 2013), all three participants were more accommodating rather than resistant to adhere to the standards of English academic written discourse. As mentioned above, Kipnis (2011) describes Chinese education as relying heavily on the teacher as an exemplary model and figure of authority. In agreement with this notion, all three interviewees seemed puzzled when asked if they had ever thought to do something in a different way than what the teacher asked. Kelvin summed it up by saying, "my teacher wants this right. I don't think about doing other ways. I always follow the teacher. I think most students don't have that kind of feeling to insist to write it their way". Furthermore, both Fiona and Kelvin's parents were described as viewing the U.S. as having more symbolic power than China in the way of educational returns and this likely had a strong effect on how these students shaped their own imagined communities within a U.S. university context.

Finally, and perhaps most interestingly, there were signs that the three participants felt what Liu and Tannacito (2013) would call an 'inferiority of identity'. For example, all three students were in the process of negotiating their L2 writing identity and seemed in agreement, overall, that English argumentative writing is easier for the reader to understand than Chinese argumentative writing. Levitt described Chinese writing as "weak" because the relationships between ideas were not as direct as in English. While he recognized that this so---called "weakness" is dependent on cultural context, he also pointed out that more people can read English than Chinese on a global scale and English is just a "faster way to communicate" because it is easier to learn than Chinese and more direct. All three participants also noted that their Chinese writing skills had deteriorated due to their concentration on English writing. This seems to underline Kumaravadivelu's (2006) premise that Western methods take precedence over local practices and the 
hegemony of English as the dominant discourse becomes reified and legitimated.

\section{Conclusion and Future Directions}

There were several limitations to this study that bear some explanation. First of all, it is obvious that analyzing data from three participants is in no way conclusive evidence to support or refute the main research questions in this study. However, it is hoped that this small---scale ethnographic study provides a starting point for further exploration of L2 English identity negotiation by Chinese language learners studying in the U.S. and fulfilling their introductory composition course requirement. Another caveat lies in the fact that the composition course in question serves as a gatekeeper for admission to highly coveted spots in the Business School. Students are not likely to show much evidence of resistance to teaching methods when they know they need to achieve a B or better to qualify for admission. Furthermore, member checking of interview data was less than ideal due to the students' return to China for the summer after the end of the semester. More discussion of the transcripts and the results of the data analysis with the participants would be useful at a later date to better clarify some of the points made beyond asking multiple questions in a similar way during the interview itself. Another weakness of this study was the short time frame. Constraining the study to a single semester did not allow for a more longitudinal observation of students' progress and comparison of their perspectives over different points in time. In the future, it would also be interesting to include examples from student papers to provide further triangulation of the data.

To conclude, there is no doubt that English academic writing will remain an important determiner of success for L2 English university students studying both in the United States and their home countries. A majority of Chinese students and their parents will also likely continue to view studying abroad in English---medium higher educational institutions as helpful to gaining better employment opportunities. This small---scale study serves as an important reminder that Chinese international students are not a homogenous entity, but each one comes with a unique package of educational desires, imagined communities, and views on schooling. While there were no extreme differences in opinion between the three students interviewed here, it is still evident that they had unique perspectives and goals for learning English and different degrees of inferiority or 'othering'. Future research exploring the extent to which they self---marginalize or feel positioned as an 'Other' or outsider in the community of practice of a U.S. university or their own imagined communities both within and outside the composition classroom merits continued investigation.

\section{References}

Atkinson, D. (1999). Scientific discourse in sociohistorical context: The Philosophical Transactions of the Royal Society of London, 1675-1975. Mahwah, NJ: L. Erlbaum.

Bourdieu, P. (1991). Language and symbolic power. Harvard University Press. 
Canagarajah, S. (2004). Multilingual writers and the struggle for voice in academic discourse. Negotiation of identities in multilingual contexts, 45, 266.

Canagarajah, A. S. (2013). Literacy as translingual practice: Between communities and classrooms. Routledge.

Chiang, Y. \& Schmida, M. (1999). Language identity and language ownership: Linguistic conflicts of first-year university writing students. In P.K. Matsuda, M. Cox, J. Jordan, \& C. Ortmeirer-Hooper (Eds.), Second language writing in the composition classroom: A critical sourcebook (pp. 89-102). Urbana, IL: Bedford/St. Martin's.

Chowdhury, R. \& Phan, L. H. (2014). Desiring TESOL and International Education: Market abuse and exploitation. Bristol: Multilingual Matters.

Ferris, D. (2014). Language power. Boston: Bedford/St.Martin's. Institute of International Education (2015). Open Doors 2014: Report on International Educational Exchange. Sewickley, PA: IIE Books.

Kipnis, A. (2011). Governing Educational Desire: Culture, politics, and schooling in China. Chicago and London: University of Chicago Press.

Kumaravadivelu, B. (2006). TESOL methods: Changing tracks, challenging trends. Tesol Quarterly, 59-81.

Liu, P. H. E., \& Tannacito, D. J. (2013). Resistance by L2 writers: The role of racial and language ideology in imagined community and identity investment. Journal of Second Language Writing, 22(4), 355-373.

Norton, B. (1997). Language, identity, and the ownership of English. TESOL Quarterly, 31(3), 409-429.

Norton, B. (2001). Non-participation, imagined communities and the language classroom. Learner contributions to language learning: New directions in research, 6(2), 159-171.

Norton, B., \& Toohey, K. (2011). Identity, language learning, and social change. Language Teaching, 44(04), 412-446.

Saldaña, J. (2009). The coding manual for qualitative researchers. London: Sage. 
JENNIFER LUND PAGE $\mid 75$

\section{Appendix A}

\section{Essay 3: Argument}

A 1400---1600 word paper, with an APA---formatted Works Cited page All of the sources (5---7) from your annotated bibliography

\section{The Assessment}

To construct an insightful, argumentative response to your "research question." As the final step in your sequenced writing project, you will offer a "critical stance" on the issue through a thesis stating your claim. The critical position you take should demonstrate how deeply you have investigated your issue.

\section{Strategies}

- Write an informative (and brief!) introduction in which you frame your argument, orient an unfamiliar reader to the issue, discuss and justify its need or significance, and clearly articulate your position (your "main claim").

- Develop your position with three-four reasons to support your thesis that are interesting, original, and effective (and based on your research!). Each of these reasons should represent ideas or perspectives that are necessary for the reader to understand your claim. They should not simply summarize the main ideas of the sources you have read.

- Discuss the connections between your sources for each of the reasons you give (synthesize the sources to support each reason using the Sandwich Model).

- Include a counterargument and then respond to it with evidence or examples (this is sometimes called "counterarguing").

- Write a conclusion that "echoes" the introduction and leads the reader to a new point or realization about your argument. This can include a call to action, a suggestion about what needs to be done next, a new critical question, or any other strategy that helps the reader understand "Why should I care about what I have just read?"

\section{Criteria for Evaluation}

1. Analysis: Does the paper demonstrate true insight in terms of how it draws upon outside sources to support the author's "thesis statement"?

2. Structure: Does the paper's orchestration of the different outside sources and voices it draws upon seem as elegant and logical as possible?

3. Language: Has the author dealt with both his/her own argument as well as other authors' arguments with seriousness and respect at an appropriate academic register with varied vocabulary?

4. Style: Is the paper's "scaffolding" well-constructed (including enough "attributive tags", signal phrases, transitions) 


\section{Appendix B}

Sample Interview Questions - Student Participants

\section{First Interview}

- What is your purpose/goal of learning English?

- What does better English mean to you?

- Why do you learn English academic writing?

- In your opinion, what comprises good writing?

- What do you expect to learn in the writing class?

- How does learning how to write in English affect your thinking and identity?

\section{Second Interview}

- What are the similarities and differences between English and Chinese writing styles?

- What are some difficulties you encounter in writing in English?

- Can you express your personal thoughts and feelings in English writing?

- How would you write about this (one of the students' writings) in your first language?

- Why would an American professor or your writing teacher accept some writings and not other writings?

- What are the differences between your essays and academic discourse?

- What are the strengths/limitations of both discourses?

\section{Final Interview}

- What is taught/learned in the class?

- Can you talk about the organization/textbooks/assignment/activities of the class?

- Which subject or what content in the textbook do you enjoy the most? Which do you think is the most useful?

- Which assignment or project do you work the hardest? Which do you think is the most useful? (If necessary, please define useful.)

- How much effort do you put into the course outside/inside the class?

- Are you satisfied with the curriculum/pedagogy of the course?

- What suggestion would you give to improve the course?

- Can you recall a situation when you insisted on doing things your teacher doesn't like in class or in English writing?

\section{Author Note}

Correspondence concerning this article should be addressed to Jennifer Lund, Department of Literacy, Culture, and Language Education, Indiana University, 201 N. Rose Avenue, Bloomington, IN, 47405. Contact: lundj@indiana.edu 